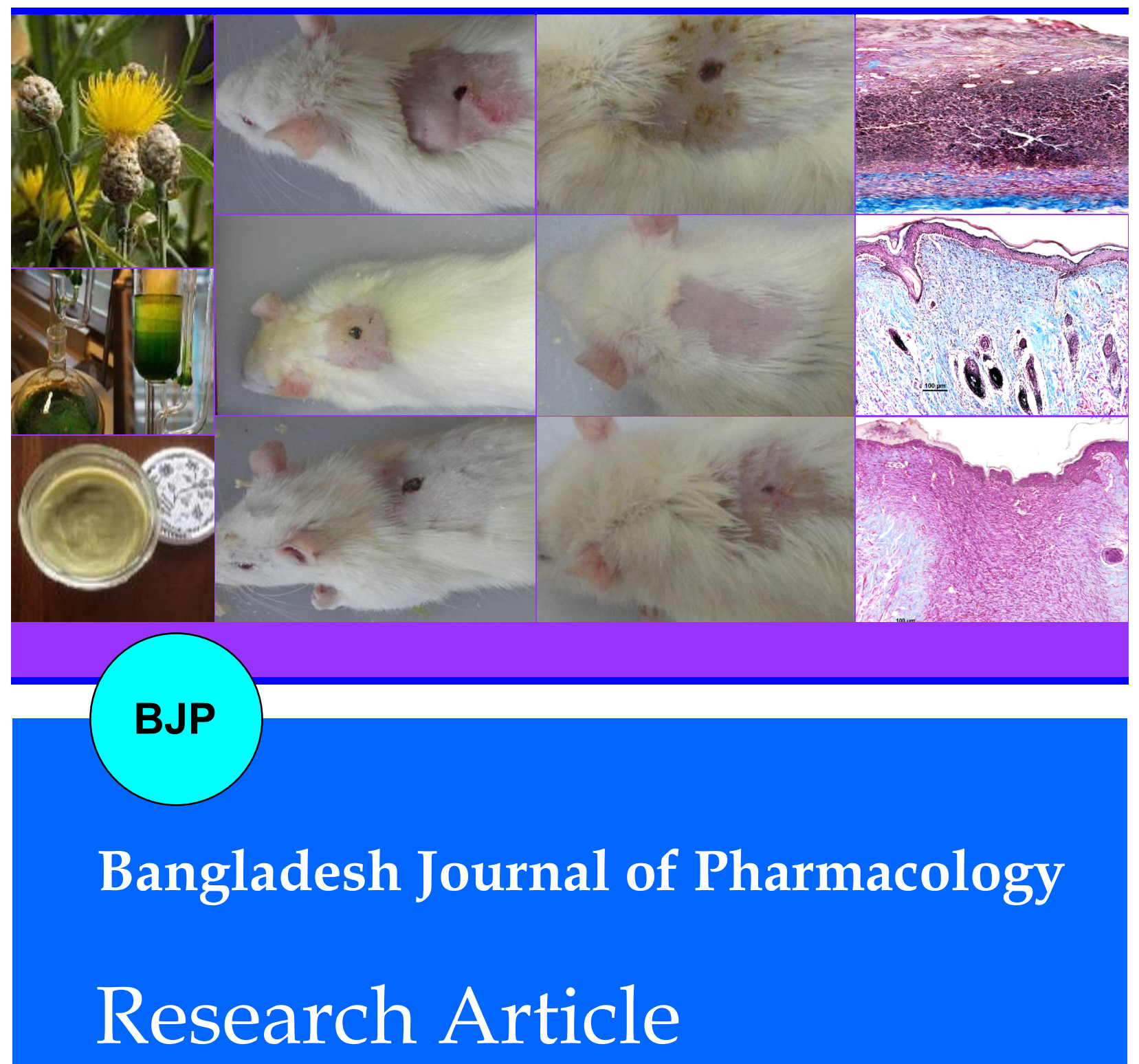

Wound healing effect of different extracts of Centaurea pterocaula 


\section{Wound healing effect of different extracts of Centaurea pterocaula}

\section{Barış Ötün'1 and Ufuk Mercan Yücel²}

${ }^{1}$ Bitlis Eren University Hizan Vocational School, Bitlis, Turkey; ${ }^{2}$ Van Yüzüncü Yıl University, Faculty of Veterinary Medicine, Department of Pharmacology and Toxicology, Van, Turkey.

\begin{tabular}{|c|c|}
\hline \multicolumn{2}{|l|}{ Article Info } \\
\hline Received: & 2 October 2018 \\
\hline Accepted: & 4 January 2019 \\
\hline Available Online: & 14 January 2019 \\
\hline \multicolumn{2}{|c|}{ DOI: 10.3329/bjp.v14i1.38444 } \\
\hline \multicolumn{2}{|c|}{$\begin{array}{l}\text { Cite this article: } \\
\text { Ötün B, Yücel UM. Wound healing } \\
\text { effect of different extracts of Centaurea } \\
\text { pterocaula. Bangladesh J Pharmacol. } \\
\text { 2019; 14: 9-16. }\end{array}$} \\
\hline
\end{tabular}

\begin{abstract}
In this study, the effect of different extracts of Centaurea pterocaula were evaluated on $6 \mathrm{~mm}$ wound created by punch biopsy on the rat back. The leaves of the plant were powdered and extracted with distilled water, methanol, $n$-hexane and ethyl acetate. Extracts were obtained in the form of pomade with vaseline and applied topically to the wounds. The wound measurements performed on day $0,2,4,6,8,10$ and 12 and the histopathological examination performed on day 12 . The $n$-hexane extract had an accelerating effect on wound healing and made a positive contribution to the healing process. In conclusion, C. pterocaula has a promising future for new drug development studies by its wound healing property.
\end{abstract}

\section{Introduction}

Wound healing is the whole of sequential, complex, cellular, physiological and biochemical events that occur in response to tissue damage in the organism as a result of tissue damage caused by traumatic, surgical or idiopathic various diseases (Witte and Barbul, 1997). Any delay or negativeness that will occur in this process will result in un-closure of the wound and delay in healing. Delayed wound closure or opening of the wound still maintains its importance as a current problem in surgery.

There are many products on the market under the name of medical dressing materials for the treatment of wound healing. However, the availability of these medical dressings available on the market is not easy and it brings an additional burden in terms of cost. Therefore, an attempt to search for the product that could be an alternative to medical dressings on the market in the treatment of chronic wounds was made performed. It has been shown that many alternative products affecting through various mechanisms in wound healing could be used for this purpose. Medicinal plants have been used for centuries for the treatment of dermatological disorders such as skin disorders and in particular cuts, wounds, burn (Jain et al., 2006; Mirmalek et al., 2015; Firdous and Sautya, 2018).

Many species of Centaurea type which is one of them have long been used in traditional medicine, and still, numerous species are used in folk medicine in Anatolia. Centaurea species are used in the popular medicine alone or together with another plant for the purposes of anti-diabetic, anti-diarrhea, anti-rheumatic, anti-inflammatory, cholagogue, choleretics, digestive, stomachic, diuretic, pesticide, astringent, hypotensive, antipyretic, cytotoxic, antibacteria (Barrero et al., 1997; Baytop, 1999). For instance, C. drabifolia, C. pulchella and C. solsitalis are used in abscess, hemorrhoids and cold treatments, C. aspera is used to lower blood sugar, C. behen is used in the treatment of jaundice and as aphrodisiac, C. calcitrapa is used in diuretic, cleansing, tonic effect and jaundice and cold treatments, $C$. cyanus is used as diuretic, astringent. Besides, C. acaulis, C. centaurium, C. cyanus, C. monantha, C. nigra, C. Salonitana and C. scabiosa have anti-cancer and anti-tumor properties (Grieve, 1977; Sezik et al., 2001).

Centaurea Pterocaula Trautv is commonly found in Turkey and especially in the Eastern Anatolia Region. 
This plant is known by the name of "Çoruşbozan" in Turkey and used as vulnerary in public, by crushing and powdering its leaves (Altundag and Ozturk, 2011).

Although it is used for wound healing by people and wound healing effects of different Centaurea species were investigated in previous studies, no research was encountered for the determination of wound healing effect of C. pterocaula. Therefore, in this study, experimental determination of whether C. pterocaula has wound healing effects and thus, making a contribution to skin wounds with serious effects on human life are aimed.

\section{Materials and Methods}

\section{Chemicals}

Methanol, $n$-hexane and ethyl acetate were supplied from the Sigma-Aldrich. The vaseline was supplied from the Akkimya. All chemicals and reagents used were of analytical grade.

\section{Experimental animals}

In this study, 56 male Wistar-Albino rats with the average weight of 150-250 g were used. Rats were housed in rooms with 12 hours light/dark lighting up, automatically adjusted temperature $\left(22 \pm 2^{\circ} \mathrm{C}\right)$ and humidity $(45-50 \%)$ again in the same place during experiment, and they were fed with city water supply and standard pellet diet (Van Feed Factory), food and water intake were made free.

\section{Plant material collection}

The leaves of C. pterocaula was collected from the step located in Tanriverdi hamlet connected to Konalga Village of Çatak District of Van Province with $2200 \mathrm{~m}$. altitude in August 2013 (GPS values: 37 50' 992" N, 43 09' $828^{\prime \prime}$ E) and identified by Mr. Fevzi Özgökçe, Department of Biology, Faculty of Art and Sciences, Van Yüzüncü Yil University. They were dried in the Herbarium (voucher No.: 163783) and stored.

\section{Preparation of the extracts}

The leaves were triturated with the help of grinder (Lavion). $25 \mathrm{~g}$ was taken from powdered plant samples for each extract and subjected to extraction for 24 hours in soxhlet device (Elektromag 6MX25, Turkey) so long as to be aqueous, ethanol, $n$-hexane and ethyl acetate and $500 \mathrm{~mL}$ from each solvent. After the extraction, the solvents were removed from the evaporator (Heidolph Laborota 4001 digital). The extracts obtained were mixed until being homogenized with vaseline and 4 products in the form of pomade were obtained.

\section{Experimental design}

Fifty-six male rats were divided into 7 groups, including 8 animals in each group. These groups were made up as follows, including four of them with the application of different extracts, and three of them as the control group.

Methanol extract group: The pomade prepared with methanol extract (about $0.5 \mathrm{~g}$ ) was administered to the wound area in the back of rats. Ethyl acetate extract group: The pomade prepared with ethyl acetate extract (about $0.5 \mathrm{~g}$ ) was administered to the wound area in the back of rats. n-Hexane extract group: The pomade prepared with n-hexane extract (about $0.5 \mathrm{~g}$ ) was administered to the wound area in the back of rats. Aqueous extract group: The pomade prepared with aqueous extract (about $0.5 \mathrm{~g}$ ) was administered to the wound area in the back of rats. Vehical group: Only 0.5 $\mathrm{g}$ vaseline was administered every day to the wound area in the back of animals throughout the study to assess the effect of vehicle material on the wound in these extracts prepared in the form of pomade. Reference group: Every day, only $0.5 \mathrm{~g}$ Madecassol ${ }^{\circledR}$ was administered to the wound area of rats as a reference drug. The reason for choosing this ointment as a reference drug is the fact that contains plant extract as an active ingredient. Because $1 \mathrm{~g}$ of this ointment had titrated extract of $10 \mathrm{mg}$ Centella asiatica. Control group: Every day, only $0.1 \mathrm{~mL}$ normal saline was administered to the wound area in the back of animals in this group throughout the study.

\section{Histopathological study}

At the end of day 12, the wound area containing approximately $2 \mathrm{~mm}^{2}$ where the wound was located in sacrificed animals was shaved, and tissue samples containing epidermis and dermis were taken into the formalin solution (10\% buffered neutral) and fixed for 24 to 48 hours. After washing and routine tissue monitoring, they were blocked with parablast. Thick sections $(6 \mu \mathrm{m})$ were taken from the blocks. The sections were stained with Mallory's triple stain (Bancroft and Cook, 1984). The necessary areas were photographed.

\section{Statistical analysis}

Statistics for the emphasized property (wound space) were expressed as the average and standard deviation. In terms of this property, two-factor and one of the factors repeated measurement variance analysis was performed in comparing the group averages and periods (day 0-12). After the variance analysis, Tukey's multiple comparison test was used to determine different groups. The statistical significance level was taken as $5 \%$ in calculations, and SPSS statistical software was used for calculation.

\section{Results}

When we evaluate the groups according to differences between them, the difference between the days up to 
day 10 in methanol extract and the ethyl acetate extract group and up to day 8 in other groups was statistically significant (Table I). But after the days specified, there was no statistically significant difference between the days.

When we evaluate the results based on the difference between the groups depending on the days, no statistical difference was determined between groups on day 0 , the significant difference was determined between $n$ hexane extract group and vehicle group on day 2 . However, no statistical difference was determined between other groups (Table I). On day 4, there were statistically significant differences between the methanol extract group and 5 groups (ethyl acetate extract, $n$ hexane extract, vehicle, reference, control) and between the aqueous extract group and 5 groups (ethyl acetate extract, $n$-hexane extract, vehicle, reference, control; Figure 1). On day 6 and 8, statistically significant differences were determined between the methanol extract group and other groups and between ethyl acetate extract group and other groups (Figure 2). While

\section{Box 1: Skin Wound Creation and Monitoring}

\section{Principle}

The purpose is to study the cellular and molecular pathways involved in wound repair and regeneration. Full thickness excision wound is created on the dorsum of the rat. The diameter of the wound is measured at regular interval and the wound closer rate is calculated based on wound area in relation to original size.

\section{Requirements}

Sterile circular biopsy punch $(6 \mathrm{~mm})$; Digital caliper; Electric shaver; Formalin; Ketamine hydrochloride; Millimetric acetate paper; Povidone-iodine; Rat; Syringe

\section{Procedure}

Creation of skin excisional wound

Step 1: Anesthesia was achieved by giving $50 \mathrm{mg} / \mathrm{kg}$ dose $10 \%$ ketamine hydrochloride intraperitoneal to the animals that were divided into groups.

Step 2: After anesthesia, back hairs of animals were shaved with an electric shaver.

Step 3: Sterilization was achieved in a surgical operation area by applying povidone-iodine to the shaved area.

Step 4: Full-thickness wounds were created by using $6 \mathrm{~mm}$ punch in the interscapular area of the animals.

Step 5: Move the animal to a warm area

Step 6: Monitor the rat's recovery from anesthesia

Step 7: Return the rat to the cage while fully recovered

Application of pomade

Assuming the day in which wounds were created as the day 0 , pomades prepared for groups were administered topically to the wound of animals for 12 days

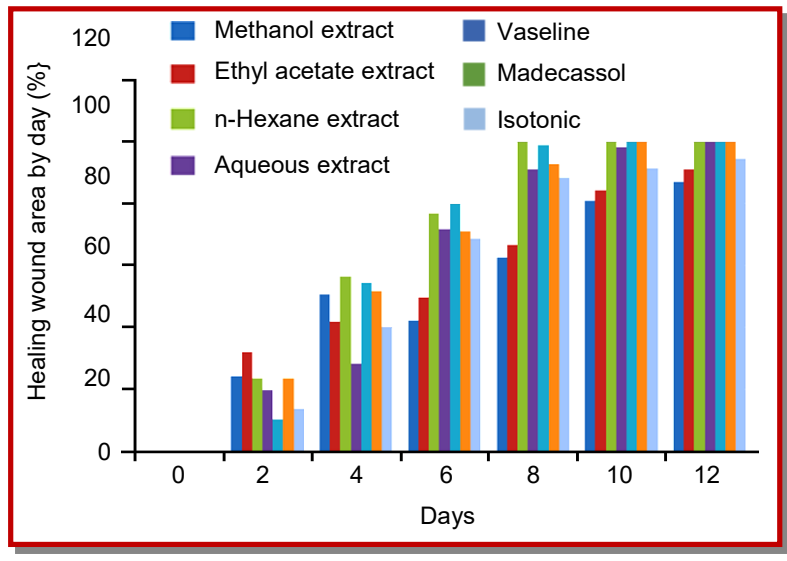

Figure 1: The healing wound area by day

there was no statistically significant difference between methanol extract group and ethyl acetate extract group on day 10, the difference between these two groups and other groups was statistically significant. On day 12 , the statistically significant difference was determined

\section{Monitoring of wound closer}

Step 1: Wound area was assessed every 2 days using millimetric acetate paper

Step 2: The wound area was calculated by the pixel count method using Adobe ${ }^{\circledR}$ Photoshop ${ }^{\circledR}$ CS4. At first, an object in the photo was chosen with its size clearly millimeter (ruler) and determine how many pixels this selected part corresponds to. Then we choose the area where we will measure the area and the program gives us that area clearly.

Histological purpose

Step 1: After harvesting the wound tissue, lay it on a sandwiched filter paper

Step 2: Place the tissue in a histological cassette for fixation in formalin $(10 \%)$ solution

Step 3: Finally follow the conventional paraffin embedding processing

\section{Notes}

1. Ketamine may be injected with lidocaine which ensure 20 min anesthesia

2. Alcohol $(70 \%)$ may be used to disinfectant the area of excision instead of povidone-iodine. Alcohol is more irritating

3. Digital caliper may be used instead of millimetric acetate paper for measuring the size of the wound

4. Analgesic may be advised (Buprenorphine $0.05 \mathrm{mg} / \mathrm{kg}$ subcutaneously every 12 hourly for the first 24 hours postoperatively)

5. The same person measured the area of the wound throughout the measurement procedure for accuracy

6. Place the wound tissue on a sandwich filter paper in order to avoid tissue folding during the fixation process

\section{References}

Moreira et al., 2015; Mirmalek et al., 2015 
Table I

Wound area comparative results different extracts Centaurea pterocaula

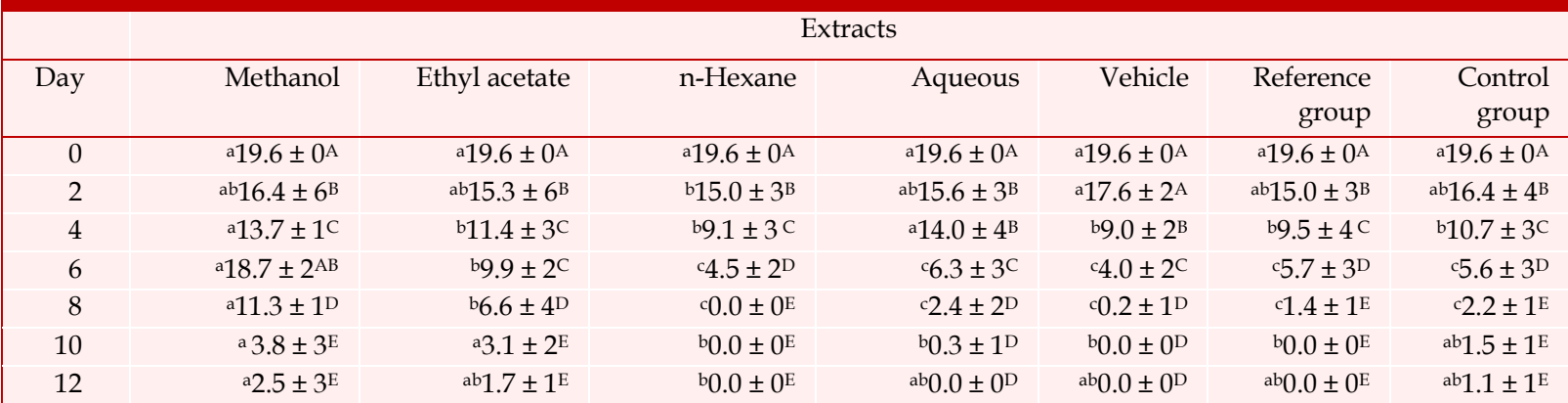

$\mathrm{p}=0.001$ group; $\mathrm{p}=0.001$ time; $\mathrm{p}=0.001$ group $\mathrm{x}$ time; $\mathrm{A}, \mathrm{B}, \mathrm{C}: \downarrow$ Difference between periods (day) with different upper case in the same column is statistically significant $(p<0.05) ; a, b, c: \rightarrow$ Difference between group with different lower case in the same row is statistically significant $(p<0.05$ )

between methanol extract group and $n$-hexane extract group, aqueous extract group, vehicle group and the reference group.

\section{Assessment of histopathological study}

As a result of the histopathological evaluation, $n$ hexane group produced the best result among various extracts of the plant (Figure 3). This group had a similar appearance with reference group and vehicle group, however, $n$-hexane group was more effective.

\section{Discussion}

When the groups were compared according to the time, differences were observed between days in each group up to day 10 in methanol and ethyl acetate extract group and up to day 8 in other groups. This difference was normal for the healing process.

When we make assessments based on the groups, while no difference was observed among groups on day 0 , the wound healing of $n$-hexane extract group was better on day 2 compared with other groups. The wound healing in $n$-hexane extract and vehicle group on day 4 and 6 were better than other groups. The wound area of methanol extract group which was close to other groups until day 6, expanded later. Wounds of $n$ hexane extract group was completely healed on day 8 . Healing was completed in the vehicle and the reference group on day 10 . On day 12 , while wound healing was completed in animals in the aqueous extract group, healing was not completed in methanol extract, ethyl acetate extract and the control groups.

When we evaluate the wound healing process according to these results, wound healing took place in a shorter time in rats with $n$-hexane extract administration. Vehicle agent (vaseline) has also the effect of accelerating wound healing. However, while vehicle agent accelerated the wound healing with $n$-hexane or by itself, this effect is not seen with methanol and ethyl acetate extracts.

When we evaluate in general, $n$-hexane extract and vehicle agent had faster wound healing effect compared with the reference group. Therefore, these two substances can be used in the treatment of wound healing. Also, the acceleration of wound healing in aqueous extract group is better than the control group. Therefore, it can be said that aqueous extract had the effect of accelerating wound healing. It cannot be said that methanol and ethyl acetate extracts have wound healing accelerating effects because they have almost the same effect with the control group. On day 6, the delay in the healing process and expansion of the wound area in methanol extract group, may be explained with the stress of animals and similar circumstances. Because there are many studies indicating that stress negatively affects and delays wound healing (French et al., 2006; Marucha et al., 1998; Padgett et al., 1998).

The wound healing accelerating effect of $n$-hexane extract may be due to the anti-oxidant, anti-inflammatory and antimicrobial effects of the substance that it solves. Because in many studies performed, it was determined that Centaurea species have anti-oxidant (Baykan Erel et al., 2014; Chougule et al., 2012; Zengin et al, 2010), anti-inflammatory (Garbacki et al., 1999; Negrete et al., 1993) and antimicrobial (Barreo et al., 1995) effects. Moreover, in their study, Tekeli et al. (2008) examined the phenolic structure and anti-oxidant effects of C. pterocaula grown in Konya and found that the plant had an anti-oxidant effect.

Plants have several compounds with the strong antioxidant activity that capture free radical and in this way neutralize free radicals such as phenolic compounds, nitrogen compounds, vitamins, terpenes and some internal metabolites. In the studies carried out, it was revealed that the anti-oxidant capacities of plant extracts are higher than synthetic anti-oxidants (Pokorny, 1991). This anti-oxidant activity of plants is closely associated with the number of secondary metabolites in 


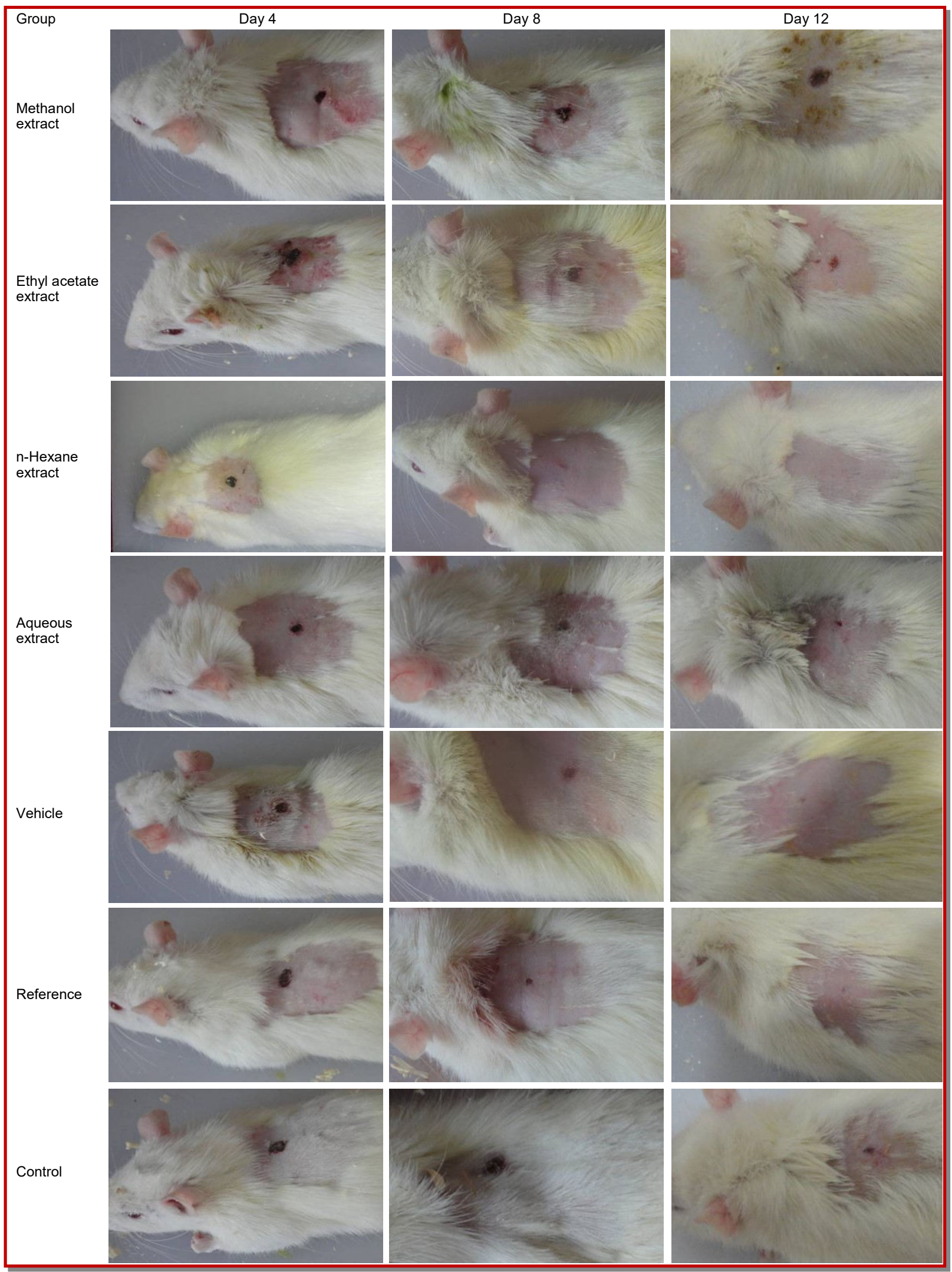

Figure 2: Macroscopic view of wound healing 


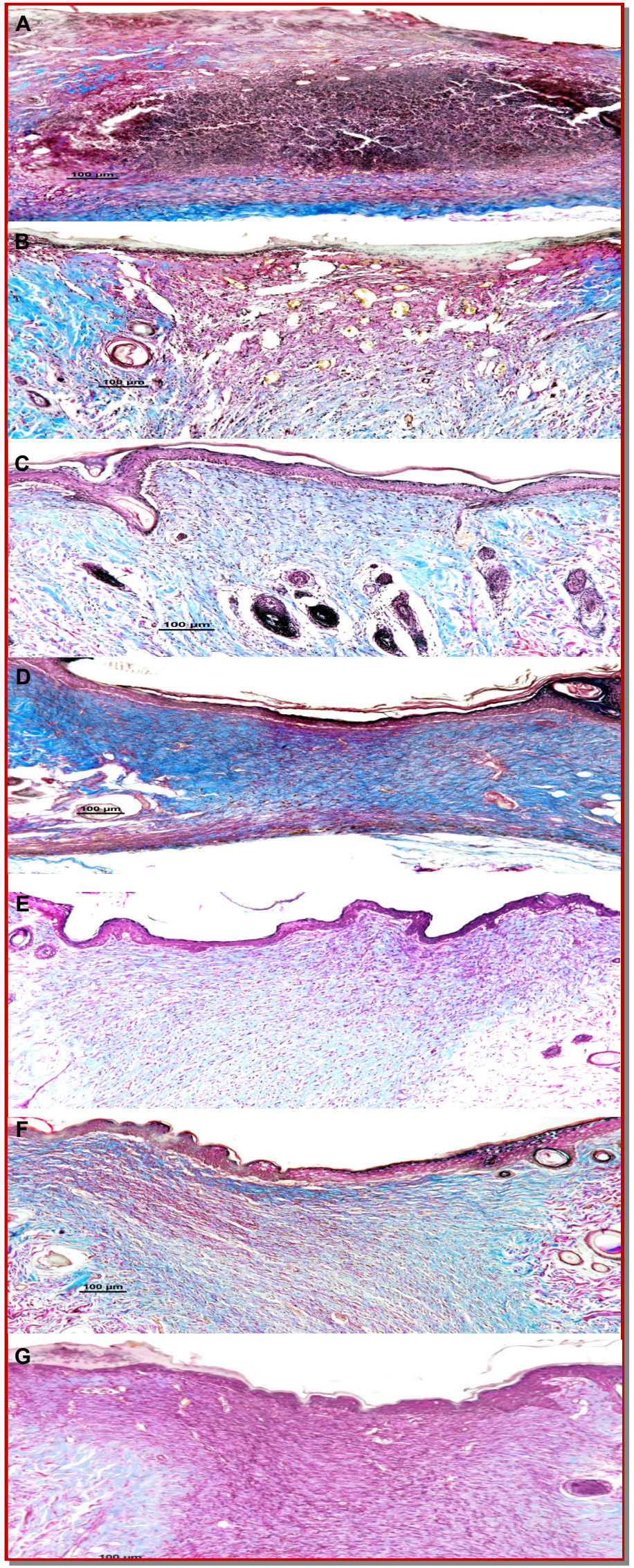

Figure 3: Histopathology of the skin of the wound area in rat after using different extracts (Masson trikrom, Bar; $100 \mu \mathrm{m})$

A: Methanol extract group; regeneration in the epidermis has not yet begun, acute purulent inflammatory exudates in the incision area and small amount of collagen tissue proliferation are monitored.

B: Ethyl acetate extract group; epidermal regeneration effort starting from wound edges at the incision site has not yet been completed, and connective tissue proliferation rich in papillary vessels in dermis is monitored.

C: $n$-Hexane extract group; regeneration has been completed in epidermis in the incision site and came to almost the same level with wound edges, proliferation poor in vascular and inflammatory cells but mature in connective tissue is monitored in the dermis

D: Aqueous extract group; regeneration has been completed in epidermis in the incision site, and regenerated epidermis have a concave appearance. Capillary blood vessels and connective tissue proliferation is monitored in dermis.

E: Vehicle group; regeneration has been completed in epidermis in the incision site, and also, the regenerated epidermis has sinuous surface and came to almost the same level with the wound edges, proliferation poor in vascular and inflammatory cells but mature in connective tissue is monitored in the dermis.

F: Reference group; regeneration has been completed in epidermis in the incision site, and regenerated epidermis has a concave appearance. Capillary vessel and connective tissue proliferation is monitored in the dermis.

G: Control group; regeneration has not been completed in epidermis in the incision site, and regenerated epidermis has a concave appearance. Capillary vessel and connective tissue proliferation is monitored in the dermis. 
their structures.

Previous chemical studies on Centaurea species demonstrated that sesquiterpene lactones (germacranolid, elemanolid, guaianolide and eudesmanolid) is systematically the most important component of this species, in addition, it was determined that they Centaurea species compounds such as steroids, triterpenes, hydrocarbons, polyacetylenes, flavonoids, alkaloids, lignans and essential oils (Kılıç et al., 2014; Wagner, 1977). Most of the sesquiterpenes are included in the composition of essential oils and are responsible for the pharmacological effects of these essential fractions. Sesquiterpene lactones are compound groups with important biological activities but scarcely found in nature and their very different biological activities such as antimicrobial, antitumoral activities are reported (Robbers et al., 1996). Also, polyacetylenes, flavonoids (flavones, flavonols, flavanones and flavanonols) and other phenolic compounds (cinnamic acid derivatives characteristically) (Wagner, 1977) included in this species are other important and characteristic compounds of this species. Flavonoids have anti-oxidant (Cao et al., 1997; Rice-Evans et al., 1996), anti-inflammatory (Ferrandiz and Alcazar, 1991), antimicrobial (Cushnie and Lamb, 2005) and anti-cancer (Hertog et al., 1993) effects by affecting various metabolic pathways such as glycolytic enzymes and protein synthesis as well as free radical scavenging activities.

Koca et al. (2009) examined the wound healing and anti -inflammatory activities of C. iberica, a species of Centaurea, and reported that methanol extract had a remarkable wound-healing effect and showed significant dose-dependent anti-inflammatory activity. Csupor et al. (2010) examined the wound healing effect of different extracts of C. sadleriana on rats and determined that $n$-hexane fractions of the methanol extract of this plant significantly accelerated wound healing and confirmed the traditional usages as a result of regular topical applications. Akkol et al. (2011) investigated the wound healing effect of Achillea biebersteinii, tested different extracts on rats and found that $n$-hexane extract had better wound healing activity compared with other extracts. Das. (2013) investigated the wound healing effects of aqueous extract of Stevia rebaudiana and tested aqueous extracts prepared at different doses. The wound healing effect of aqueous extracts prepared from Stevia rebaudiana leaves was demonstrated, and it was found that its effect could increase depending on the dose. Gopalakrishnan and Rajameena (2012) investigated the wound healing efficiency of different extracts of Desmodium gyrans DC (Fabaceae) leaves on rats and determined that ointment form prepared by the ethanol extract of the plant increased the wound contraction and skin tensile strength compared with the control group. Kosger et al. (2009) examined the wound healing effects of plant root extracts of Arnebia densiflora prepared with $n$-hexane on rats and stated that $10 \%$ of plant root extract had wound healing accelerating effect.

The findings of this study verify the traditional usage of C. pterocaula on wound healing and show similarity with the studies carried out by Csupor et al. (2010); Akkol et al. (2011); Kosger et al. (2009).

\section{Conclusion}

The $n$-hexane extract of C. pterocaula has the effect of accelerating wound healing according to statistical and histopathological results. The anti-oxidant phenolic compounds and flavonoids made contributions to the wound healing effect of C. pterocaula.

\section{Acknowledgement}

This work was supported by Van Yüzüncü Yll University Scientific Research Projects Directorate (grant number; 2014SBE-YL055).

\section{Ethical Issue}

The necessary permission was received (Decision number: 2013/294) from the Y.Y.Ü Animal Experiments Local Ethics Committee, animals obtained from Y.Y.Ü Experimental Medicine Research and Application Center.

\section{Conflict of Interest}

We wish to confirm that there are no known conflicts of interest associated with this publication.

\section{References}

Akkol EK, Koca U, Pesin I, Yilmazer D. Evaluation of the wound healing potential of Achillea biebersteiniiafad. (Asteraceae) by in vivo excision and incision models. Evid Based Complement Alternat Med. 2011; 20: 1-7.

Altundag E, Ozturk M. Ethnomedicinal studies on the plant resources of east Anatolia, Turkey. Procedia Soc Behav Sci. 2011; 19: 756-77.

Bancroft JD, Cook HC. Manual of histological techniques. London, Churchill Livingstone. 1984.

Barrero AF, Oltra JE, Rodriguez I, Barragan A, Gravalos DG, Ruiz P. Lactones from species of Centaurea: Cytotoxic and antimicrobial activities. Fitoterapia 1995; 66: 227-30.

Barrero AF, Herrador MM, Arteaga P, Cabrera E, RodriguezGarcia I, Garcia-Moreno M, Gravalos DG. Cytotoxic activity of flavonoids from Carthamus arborescens, Ononis natrix ssp. ramosissima and Centaurea malacitana. Fitoterapia 1997; 68: 281-83.

Baykan Erel Ş, Ballar P, Karaalp C. Anti-oxidant activities of 
phenolic compounds of Centaurea ensiformis P.H. Davis. Turk. J Pharm Sci. 2014; 11: 19-24.

Baytop T. Treatment with plants in Turkey. İstanbul, Nobel Bookstore, 1999.

Cao G, Sofic E, Prior RL. Anti-oxidant and prooxidant behavior of flavonoids: Structure-activity relationships. Free Radic Biol Med. 1997; 22: 749-60.

Chougule P, Pawar R, Limaye D, Joshi YM, Kadam V. In vitro anti-oxidant activity of ethanolic extract of Centaurea behen. J Appl Pharm Sci. 2012; 2: 106-10.

Csupor D, Blazsó G, Balogh Á, Hohmann J. The traditional Hungarian plant Centaurea sadlerianaJanka accelerates wound healing in rats. J Ethnopharmacol. 2010; 127: 193-95.

Cushnie TP, Lamb AJ. Antimicrobial activity of flavonoids. Int J Antimicrob Agents. 2005; 26: 343-56.

Das K. Wound healing potential of aqueous crude extract of Stevia rebaudiana in mice. Rev Bras Farmacogn. 2013; 23: 35157.

Ferrandiz ML, Alcazar MJ. Anti-inflammatory activity and inhibition of arachidonic acid metabolism by flavonoids. Agents Actions Suppl. 1991; 32: 283-88.

Firdous S, Sautya D. Medicinal plants with wound healing potential. Bangladesh J Pharmacol. 2018; 13: 41-52.

French SS, Matt KS, Moore MC. The effects of stress on wound healing in male tree lizards (Urosaurus ornatus). Gen Comp Endocrinol. 2006; 145: 128-32.

Garbacki N, Gloaguen V, Damas J, Bodart P, Tits M, Angenot L. Anti-inflamatory and immunological effects of Centaurea cyanus flower-heads. J Ethnopharmacol. 1999; 68: 235-41.

Gopalakrishnan S, Rajameena R. Evaluation of ethanolic extract of Desmodium gyrans DC leaves on wound healing activity in rats. Pharm Anal Acta. 2012; 3: 3-7.

Grieve M. A modern herbal. Courier Corporation, 2013.

Hertog MGL, Hollman PCH, Katan MB. Intake of potentially anticarcinogenic flavonoids and their determination in the Nederlands. Nutr Cancer. 1993; 20: 21-29.

Jain M, Tyagi AK, Khurana JP. Molecular characterization and differential expression of cytokinin-responsive type-A response regulators in rice (Oryza sativa). BMC Plant Biol. 2006; 6: 1-11.

Kılıç Ö, Esim N, Güneş H. Chemical composition of two Centaurea (Asteraceae) kind from Turkey. The National Biology Congress, 23-27 June 2014, Eskisehir, Turkey.

Koca U, Süntar IP, Keleş H, Yeşilada E, Akkol EK. In vivo antiinflamattory and wound healing activities of Centaurea iberica Trev. ex Spreng. J Ethnopharmacol. 2009; 126: 551-56.

Kosger HH, Ozturk M, Sökmen A, Bulut E, Ay S. Wound healing effects of Arnebia densiflora root extracts on rat palatal mucosa. Eur J Dent. 2009; 3: 96-99.

Marucha PT, Kiecolt-Glaser JK, Favagehi M. Mucosal wound healing is impaired by examination stress. Psychosom Med. 1998; 60: 362-65.

Mirmalek SA, Parsa T, Parsa Y, Yadollah-Damavandi S, SalimiTabatabaee SA, Jangholi E, Hosseini S, Ashkani-Esfahani S, Abooghadareh $\mathrm{H}$, Haghighifard E. The wound healing effect of Iris forentina on full thickness excisional skin wounds: A histomorphometrical study. Bangladesh J Pharmacol. 2015; 11: 86-90.

Moreira CF, Cassini-Vieira P, da Silva MF, Barcelos LS. Skin wound healing model: Excisional wounding and assessment of lesion area. Bio-protocol 2015; 5: e1661.

Negrete R, Backhouse N, Cajigal I, Delporte C, Cassels BK, Breitmaier E, Eckhardt G. Two new anti-inflamatory elemanolides from Centaurea chilensis. J Ethnopharmacol. 1993; 40: 149-53.

Padgett DA, Marucha PT, Sheridan JF. Restraint stress slows cutaneous wound healing in mice. Brain Behav Immun. 1998; 12: 64-73.

Pokorny J. Natural anti-oxidants for food use. Trends Food Sci Technol. 1991; 9: 223-27.

Rice-Evans CA, Miller NJ, Paganga G. Structure-anti-oxidant activity relationships of flavonoids and phenolic acids. Free Radical Biol Med. 1996; 20: 933-56.

Robbers JE, Speedie MK, Tyler VE. Pharmacognosy and pharmacobiotechnology. Baltimore, Wolter Kluwer Publishers, 1996.

Sezik E, Yeşilada E, Honda G, Takaishi Y, Takeda Y, Tanaka T. Traditional medicine in Turkey $X$. folk medicine in Central Anatolia. J Ethnopharmacol. 2001; 75: 95-115.

Tekeli Y, Sezgin M, Şanda MA. Phenolic structure and antioxidant effect of Centaurea Pterocaula Trautv. that grow in Konya. Sci J Süleyman Demirel Univ Sci Lit Faculty (e-Mag). 2008; 3: 35-41.

Wagner H. Cynareae: Chemical review. In: The biology and chemistry at the compositae. Heywood VH, Harborne JB, Turner BL (eds). London, Academic Press Inc., 1977.

Witte MB, Barbul A. General principles of wound healing. Surg Clin North Am. 1997; 77: 509-28.

Zengin G, Cakmak YS, Guler GO, Aktumsek A. In vitro antioxidant capacities and fatty acid compositions of three Centaurea species collected from Central Anatolia region of Turkey. Food Chem Toxicol. 2010; 48: 2638-41. 